\title{
How Are We Pediatricians Different?
}

As we all know that children are not small adults, it goes without saying that neither Pediatrics nor Pediatricians are miniaturized versions of their counterparts in adult domain. Though there are innumerable differences that make us unique, I have tried to touch upon only a few for the sake of brevity.

To begin with, our waiting rooms are not like waiting rooms of physicians dealing with adult patients, where patients unknown to each other even avoid making eye contact. On the contrary, ours are one of the noisiest places - second only to shopping malls - resonating with noise, cries and laughter. Though sometimes there are small fights but nothing that a chocolate cannot settle.

Grown-up patients and their doctors have a different kind of relationship, with doctors being respected as some kind of authority figures. In pediatrics, however, it is generally the other way round. Children are given more respect by their doctors who realize that they need their clients' favour in order to examine them. A 'no' from a child is a strict 'no', sure to cast doom on any prospect of physical examination by his doctor. Kids nowadays are really smart and confident, and you cannot help but pay attention to what they have to say. Only the other day, I was told by a wise little boy, "Don't ever give injections to children. It's not a nice thing to do to make children cry!" Well, he had a point!

Children are very honest with their remarks and sometimes it makes them all the more funny. There are not many boring moments in a pediatric clinic. Once while trying to persuade a child to get vaccination, I told him that it will not hurt him any more than a mosquito bite. He was quick to reply: "But mosquito bites are not that painless."

Talking about the weather does not work with us to break the ice during consultations, but knowing and talking about children's favourite cartoon characters is really helpful. Most of us know about Doraemon, Chhota Bheem and the likes more than most adults. How thankful
I am to my own kids, with whom I am forced to watch their favorite cartoon shows. Complementing the children about their dresses or toys helps to gain their trust and building up of rapport, like nothing else.

The practice of pediatrics comes with its own unique professional hazards. For example, some babies have really strong pair of lungs as proved by their cry, and it makes me wish that I could keep my stethoscope in my ears a little longer than needed, just to avoid the auditory onslaught. Getting poo stains and sprinkle with a stream of urine are parts of a routine day's work of a pediatrician. On the positive side, we are not repulsed by a dirty nappy and may actually jump at the opportunity of looking at one if the baby is brought with the complaint of diarrhea. Having loads of experience of feeding babies and changing nappies during nursery duties may actually prove very useful at home, and win appreciation from one's spouse!

Though children can get really mad over something they do not like (e.g. getting jabs), they are not the ones to hold grudges and all is forgiven and forgotten by the next visit.

All said and done, there is nothing comparable in Adult medicine that gives as much pleasure as watching a child smile or laugh at you - having improved with your treatment. Being part of the childhood of a lot of children, watching them grow and achieve different milestones along the way gives immeasurable satisfaction about the work we pediatricians do!

Dhiraj Ahlawat B-105, Parsvnath Platinum Apartments, Swarn Nagri, Greater Noida, UP, India. dr.d.ahlawat@gmail.com

Editor's note: Taking care of the health needs of children is indeed a serious business but does have its funny side as well. We invite our readers to share with us any non-academic literary work that will tickle our sense of humor, be it funny anecdotes, observations of patients or parents, or satirical perspectives of our profession. 